\title{
An Assessment of End-User Satisfaction of Academic Building Facilities in Tertiary Institutions in Ghana: Perspective of Staff of Wa Polytechnic
}

\author{
Moo Fortunatus Ablordeppey Elikem Ephraim* Ibrahim Adamu \\ School of Applied Science and Technology, Department of Building Technology and Estate Management, Wa \\ Polytechnic, P.O box 553, Ghana
}

\begin{abstract}
The overall satisfaction an occupant gets in the use of a building space has an impact on human comfort, behaviour, health and productivity. Majority of the world population has become urbanized with humans spending most of their time working in indoor office environment. However post occupancy evaluation of buildings has not received the much needed research attention. Thus, this study sort to identify the factors that influence end-users satisfaction of academic building facilities at Wa Polytechnic, so that measures to sustain or improve them could be proposed. The study adopted a quantitative research approach where questionnaire bordering on factors which affect users satisfaction were administered to a sample of seventy employees. The data was subsequently analyzed using relative importance index (RII). The study revealed that user's satisfaction is slightly above average with an RII value of 0.67 . The study also established that inadequate trees and green plants around the buildings had an adverse impact on user satisfaction. Also the absence of commercial activities around the building affects user satisfaction. It was thus recommended that a lot more trees and green plants should be planted around buildings to enhance indoor ventilation and users satisfaction. It was also recommended that, social amenities should be provided within the premises of institutions located off main commercial areas in town.
\end{abstract}

Keywords: Academic buildings, End-user, Indoor environment quality, Satisfaction, Tertiary institutions.

DOI: $10.7176 / \mathrm{JRDM} / 66-05$

Publication date:June 30th 2020

\section{Background}

The overall human behaviour and productivity are greatly influenced by the overall comfort of the building space within which they operate. It is thus imperative for a regular and critical assessment of the level of comfort and satisfaction of users of building space in order to understand their behavoiur and level of productivity (Costanza et al., 2007)

Humans spend most of their time indoors and the majority of the world's population lives in urban areas and work in an office environment (ASHRAE, 2013). There has been a significant global shift in the economy from the manufacturing sector towards the service and knowledge-based sectors which operate in indoor office environments (Haynes, 2008). An office condition has a high level of influence on its occupants' satisfaction and productivity (Frontczak et al., 2012; Van der Voordt, 2004).

Any technical flaw or weakness into the building system regarding the indoor environment condition and facility management deficiencies could bring sickness or negative effects on human health, or in the worst-case scenario, being exposed to this condition for a long-time has a potential to create a fatal or terminal effect on human health. Vischer (2008) believes that indoor human satisfaction parameters such as thermal, visual, acoustic, indoor air quality (IAQ), office layout, etc. physically and psychologically affect human behaviour. When humans are satisfied in their work environment, productivity goes high.

End-user satisfaction, comfort, and wellbeing are today in the center of the concerns of each consumer, user, prescriber or subscriber of products or services, and the universe of building does not escape this rule. In the face of technological advancement, climate change and the development of competition in every sphere of human endeavour, it seems paramount today to better knowing the individuals needs as to the conditions necessary to meet their satisfaction of comfortable buildings. Consistent with literature, the Wa Polytechnic as a public tertiary institution has a mixture of people using its limited academic building facilities. Thus an assessment of this nature is necessary for user-satisfaction improvement which comes with improved productivity. This study therefore aims at assessing the level of end user satisfaction of the building facilities in Wa Polytechnic. Specifically, the study sought to:

- Find out factors in the present conditions of the office building that enhance user satisfaction and comfort

- Find out adverse factors in the present condition of the office buildings that cause user discomfort and dissatisfaction

- $\quad$ Find measures that could be implemented to sustain or improve user satisfaction of the office building. 


\section{Literature Review}

Nowadays the quality of buildings and social life are two closely interacting parameters which require more careful interpretation of the users' needs. Their views, expectations and desires have to be incorporated into both the design and evaluation processes (Yi et al., 2020)

With specific reference to the experiences of buildings in academic institutions, the practice of user satisfaction should be increasingly incorporated during the ex-post (or monitoring) evaluation. This is necessary in order to verify the quality and validity of the service offered, thus activating a real co-participation of the user in the creation and improvement of the academic facilities service. In the field of the construction industry, customer satisfaction has been incorporated into the post-occupation evaluation(POE), an evaluation tool of the performance of the building in use through the combination of objective and subjective variables expressed by the occupiers (Munsami et al., 2017)

Several factors abound in literature as influencing the level of satisfaction which are thus reviewed as follows

\subsection{Indoor Air Quality and Ventilation}

Indoor air quality (IAQ) is the degree of quality of the indoor air of a building. IAQ has a high impact on office productivity. A workplace with good air quality has higher work performance in office and learning tasks such as text typing, proof-reading and mathematical tasks (Langer \& Bekö, 2013; $\mathrm{Ng}$, et al., 2012). Indoor air quality is a complex entity to measure. Various time-dependent physical and chemical parameters (such as relative humidity, temperature, level of air contaminants) are constituents of IAQ. These parameters are affected by outdoor conditions (climate), building conditions (material, structure and construction), buildings' HVAC systems (Heating, Ventilation and Air-conditioning systems), the indoor space arrangements (furnishing, furniture, equipment) as well as occupants' productivity patterns (Parajuli et al., 2016). These factors are highly interdependent and are dynamically affected by multiple variations and interactions (Parajuli et al., 2016). Indoor air quality can be managed either by increasing the ventilation rate or by reducing the air pollutant load in the air. Higher ventilation rates result in good indoor air quality. Lower indoor air quality is associated with Sick Building Syndrome (SBS) symptoms and reduced productivity (Guyot et al., 2018).

\subsection{Thermal comfort}

Thermal comfort is described as a state of mind which expresses satisfaction with the thermal environment (Enescu, 2017). Achieving overall thermal comfort in a building is a complex task. Thermal comfort in a building space is measured by analysing the number of discomfort complaints.

Achieving thermal comfort in a building requires energy consumption by the heating and ventilation systems in a building (Parajuli et al., 2016).

Thermal comfort plays a significant role in occupant productivity. Dissatisfaction with thermal comfort leads to productivity loss (Wang et al., 2018).. Studies indicate that temperature change within the $18^{\circ} \mathrm{C}-30^{\circ} \mathrm{C}$ range can influence the performance of office occupants in tasks like typewriting, learning performance and reading. The temperature range of $21^{\circ} \mathrm{C}-25^{\circ} \mathrm{C}$ is a stable range for office productivity.

\subsection{Lighting and Daylighting}

Office employees spend most of their time indoors thus office tasks are dependent on indoor lighting or any available day lighting. Day light is considered to be the best source of light with excellent colour rendering that offers the best light for human visual comfort. Lighting has the highest share (33\%) in the calculation of average electricity consumption in the global office buildings (Dubois et al., 2016). Artificial lighting utilizes $25-40 \%$ of the total commercial buildings' energy consumption (Narangerel et al., 2016). In the urban areas, lighting contributes to $33 \%$ of total energy consumption in offices (Rattananavathong et al., 2017). This highlights the occupants' dependence on artificial lighting in an office. Efficient day lighting measures and intelligent lighting systems can help reduce the artificial energy load and thus the carbon footprint of a building.

Organizations that pay attention to the importance of day lighting achieve higher occupant productivity in their workplaces. Building occupants prefer natural light/sunlight over artificial light (Narangerel et al., 2016). Occupant preference is due to physical, physiological and psychological reasons. Human visual system parameters such as visual size, luminance contrast, colour difference, retinal image quality and retinal illumination jointly affect the work performance of any task. Natural light's levels are above the order of magnitude of normal electric lighting levels. They influence melatonin, a hormone responsible for regulating the body's internal clock and these light levels. A study of office workers focusing on the importance of windows and their benefits reports that almost $99 \%$ believed that offices should have windows and that $86 \%$ considered day lighting to be the preferred source of light for office tasks (Al-Ashwal \& Hassan, 2018)). The literature confirms occupants' liking of windows. Daylight analysis lays the path to the day lighting strategies of side-lighting (windows) and top-lighting (skylights, roof monitors) (Van Duijnhoven, 2016). The Daylight Factor is the percentage of outdoor light under overcast skies available indoors. It takes three components into account; the sky component (SC), the light from external 
surfaces/externally reflected component (ERC) and the light reflected from surfaces within the room/internally reflected component (IRC) (Altan \& Zhang, 2018).

The recommended level of Daylight Factor (DF) for different offices depends on the type of office task. Simple tasks like reading, filling only require $1.5-2.5 \%$ daylight factor while draughting and fine machine work requires up to $8 \%$ daylight factor (Altan \& Zhang, 2018).

A low level of lighting can lead to ocular discomfort and improper lighting design leads to worker dissatisfaction. Glare-free and thermally comfortable spaces have a high effect on occupant productivity.

\subsection{Noise and Acoustics}

The World Health Organisation (WHO) describes any unwanted sound as noise. Magnitude can characterise sound (or noise). Noise and acoustics have high relevance in building design. A building's acoustic performance becomes more important in office design as most office tasks require a degree of noise control to enable the occupants to work efficiently. Bad acoustic and noise performance can lead to dissatisfaction with the office environment and can affect workers' performance (Frontczak et al., 2012). Noise in an office can have two locations for sources; external or internal. External sounds include traffic, the public, air traffic, machinery. The neutral sound pressure of a typical air-conditioned office is between $45 \mathrm{~dB}$ and $70 \mathrm{~dB}$ (Mui \& Wong, 2006). Occupant discomfort is an outcome of different Indoor Environment Qualities (IEQ). Continuous and prolonged noise at higher levels can induce and increase stress levels over time. Studies suggest that occupants subjected to continuous transport/traffic noise showed higher levels of blood pressure and stress hormones (Evans et al., 1998). Internal machinery such as fax machines, telephones and air conditioning systems can also produce annoyance that may result in similar stress levels (Ayr et al., 2003). Office-related tasks are highly affected by speech and office noise.

External building elements and design can protect the office interior from external noise. Internal arrangement and office layout influence the internal noise in the office environment. Open plan office noise can have a negative impact on the fatigue, motivation and performance of employees (Jahncke \& Halin, 2012). Tasks associated with word processing and numbers calculation are affected by internal office noise. Open plan office employees are more prone to privacy issues and disturbances due to the various office sounds around them (Toftum et al., 2012 and Balazova et al., 2008). Acoustic discomfort can be reduced by maintaining low level background noise in an office environment. Acoustic comfort can also be achieved using sound absorbing materials in the room.

\subsection{Office Layout}

Office layout design is one of the leading indoor qualities that influence workplace performance and behaviour. Design, proximity and privacy influence our work pattern and performance (Haynes, 2008b and Lee, 2010). The office layout of an organisation should be well designed to ensure efficient work process to enable organisational success.

Office layout is a physical environment that influences the behaviour of the office occupants. It is also noted that female exhibit higher dissatisfaction than male counterparts (Yildirim et al., 2007). Studies indicate cellular office and flex-office have lower dissatisfaction than open-plan offices (Danielsson \& Bodin, 2009). Cellular offices allow less distraction than open-plan offices but they do not promote informal interactions and quick access to colleagues. The open-plan office has been used mainly to reduce accommodation costs, but higher density in open-plan offices also leads to a higher load regarding lighting and ventilation. This strategy affects overall environmental satisfaction and productivity (Veitch et al., 2002).

\subsection{Biophilia and Views}

We are highly responsive to nature's forms, processes and patterns (Nabhan et al., 1993). A study has provided evidence that humans have a higher level of happiness and well-being in the natural environment (MacKerron \& Mourato, 2013). We have made significant transformation to our living habits and surroundings since prehistoric times (Nabhan et al., 1993). It has led to a decrement in human well-being and happiness (Kellert et al., 2011)

Bringing natural environment or greenery inside an office has a positive effect on the occupants' satisfaction (Kellert et al., 2011 and Gray and Birrell, 2014). Greenery in offices relates positively to productivity and negatively with stress in occupants. Indoor plants help to improve indoor air quality (Lohr et al., 1996). They assist in reducing indoor air pollution by reducing the volatile organic compounds produced by different indoor furniture and synthetic materials (Grinde \& Patil, 2009). Plants and nature help in reducing stress and anxiety even when outside the building. Health benefits and happier psychological support affects workers' perception towards the workplace. Shapes, textures and the colours of the immediate environment affect building users. Studies indicate that human psychological responses vary due to different colours (Mahnke, 1996). Colour schemes and the aesthetics of an indoor environment affect human performance and productivity (Kwallek et al.,1988 and Öztürk et al., 2012). For example, the colour green reminds us of an environment that gives us calm and harmonious feelings (Ou et al., 2004).

It is the combined effect of colour, texture and the shapes of interior design in an office environment that 
leads to the overall feeling of well-being in a workplace (World Green Building Council, 2014).

It would also help in the absorption of organisational culture among the employees (Dean et al., 1997 and Vilnai-Yavetz et al., 2005).

\subsection{Location and Amenities}

The location of the building is not part of the physical envelope of a workplace. Offices located in the proximity of public infrastructure have higher appeal to the academic community (Leaman, 1995 and Duffy et al., 1992). Offices located near major public transport infrastructure have the potential to reduce $20-40 \%$ fuel usage per person (Haider et al., 2013).

Amenities' provision near the workplace can influence the satisfaction of employees and students. It is recommended to have four types of primary amenities near a work environment (World Green Building Council, 2014) these are recreational spaces/ sports facilities

\section{Research Methodology}

Research design defines a general plan and processes through which research questions in a research are answered. The research design adopted is influenced by the research questions and objectives (Saunders et al., 2009). According to Yin (2003), research design serves as a guide for researchers in gathering and analyzing research data. Bryman (2004) posited that there are basically five research design options. However Yin(2003) classified research designs as: survey, experiment, archival analysis, history and case study. According to Yin (2003) the choice of research design depends on the focus of the research whether on contemporary or historical issues, the more control the researcher has over the research variables and the type of research questions that need to be answered.

According to Saunders et al (2009) a research that is time constrained and seeks to establish a relationship between variables essentially may be described as cross-sectional research design. They argued that cross-sectional research design essentially follows a survey research strategy and also the researcher has no control over the research variables.

From the direction of this study so far, cross-sectional research design is most suitable for the study. This is principally because researcher has no influence on the research variables in this study which is consistent with the features of cross-sectional research design. The study adopted relative importance index (RII) which ranked the factors that influence end-users satisfaction in order of importance.

To assess end-user satisfaction of academic building facilities in Wa Polytechnic, a primary source of data which is a quantitative data were collected through questionnaires on employees of the institution who use these buildings. A purposive sampling technique was used to select a sample of seventy (70) employees who are office holders and thus are assigned offices in the administration block of the Polytechnic.

Usually questionnaires are developed in such a manner that requires respondents to provide answers to a series of questions or statements. The information the questionnaire seeks to espouse should be able to address the research questions, aims and objectives and at the same time be acceptable to the target group responding to the questionnaire (Brace, 2004).

Thus the questionnaires for this study were designed based on the research questions, aim, objectives and the Literature Review.

From the literature, eight key general factors were identified as being central to end-users satisfaction of buildings. Thus the questions were framed in such a way that required respondents to indicate their levels of satisfaction on five point likert scale ranging from 1 (very unsatisfactory) to 5 (very satisfactory). The data collected were analysed using relative importance $\mathbf{R}=\frac{\sum \mathbf{w}}{\mathbf{A} * \mathbf{N}}$ where, $\mathrm{W}=$ weighting given to each statement by the respondents and ranges from 1 to 5; $\mathrm{A}=$ Higher response integer (5); and $\mathrm{N}=$ total number of respondents

\section{Discussions and Interpretation of Results}

\subsection{Demography of respondent}

Sixty five out of the total of 70 questionnaires that were given out to respondents were retrieved, representing $93 \%$ response rate. The demographic breakdown of the respondents is as presented in Table 1

\section{Table 1: Demography of respondents}

\begin{tabular}{lcl}
\hline Respondents & Sex & Female \\
\hline \multirow{2}{*}{65} & Male & 20
\end{tabular}




\subsection{Analysis of factors influencing end-users satisfaction}

As indicated earlier, the data collected on the factors that affected end-users satisfaction were analyzed using relative importance index. Respondents ranked their level of satisfaction regarding some eight key factors established from literature which affect end-users satisfaction.

The relative importance index, $R I I=\frac{\sum W}{A N}$

Where RII is a measure of the average level of satisfaction of respondents with each factor as they apply to the building.

$\mathrm{W}$ is the sum of the likert scale rankings by all respondents to each factor,

A refers to the highest ranking on the likert scale, which in this case is 5

$\mathrm{N}$ is the total number of respondents being analysed, which in this case is 65 . The results of the analysis is as presented in Table 2 below.

Table 2 RII and Ranking of end-users satisfaction factors, respondent scores

$\mathrm{S} / \mathrm{N}$ Factors affecting users satisfaction

Respondents score

\begin{tabular}{llllllll}
\multicolumn{1}{c}{ Respondents score } \\
\hline \multicolumn{1}{l}{ VUSf USf } \\
Rank \\
1 & 2 & 3 & 4 & 5 & Sf & VSf & RII \\
0 & 10 & 15 & 30 & 10 & 0.72 & 5 \\
1 & 14 & 14 & 20 & 20 & 0.73 & 4 \\
0 & 10 & 10 & 20 & 25 & 0.78 & 3 \\
15 & 10 & 25 & 15 & 0 & 0.52 & 6 \\
& & & & & & \\
0 & 0 & 10 & 35 & 20 & 0.83 & 2 \\
20 & 25 & 15 & 5 & 0 & 0.41 & 8 \\
0 & 0 & 5 & 35 & 25 & 0.86 & 1 \\
15 & 20 & 10 & 20 & 0 & 0.51 & 7
\end{tabular}

7. External and internal looks of the building (design aesthetics)

8. Location and social amenities near the building

Source (Field Data)

Key: $\mathrm{VUSf}=$ very unsatisfactory, $\mathrm{USf}=$ unsatisfactory, $\mathrm{ASf}=$ averagely satisfactory $\mathrm{Sf}=$ satisfactory, $\mathrm{VSf}$ $=$ very satisfactory

\section{Discussions of results}

The relative importance index RII for this particular study ranges from 0.2 and 1 . This is because, supposing all respondents ranked a particular factor as being very unsatisfactory, then RII for that factor shall be RII $=65 *$ $\frac{1}{5 * 65}=0.2$. On the other hand, if all respondents rank a particular factor as being very satisfactory, then $R I I=65 *$ $\frac{5 * 65}{65 * 5}=1$.

Thus if RII $=0.2$ means very unsatisfactory, 0.4 means unsatisfactory, 0.6 averagely satisfactory, 0.8 means satisfactory and 1 means very satisfactory.

From the table 2 above, Indoor Air Quality and Ventilation has an RII value of 0.72 . This means that this factor is above average satisfaction according to end users. This rank $5^{\text {th }}$ of all the eight factors that were assessed. Also thermal comfort has RII value of 0.73 which also means this factor is also above average satisfaction in the view of end users. This rank $4^{\text {th }}$ amongst the eight parameter. Lighting and Day lighting has RII value of 0.78 which is also above average satisfaction and ranks $3^{\text {rd }}$ amongst the factors as being satisfactory. However design aesthetics and rooms layout have RII values of 0.86 and 0.83 ranking $1^{\text {st }}$ and $2^{\text {nd }}$ respectively. This means that respondents are near very satisfactory with the appearance and rooms lay out within the buildings they use. Noise insulation (acoustics), natural environment of the building and the location of the building vis-à-vis access to social amenities had RII values of $0.52,0.51$ and $0.41 \mathrm{rank} 6^{\text {th }}, 7^{\text {th }}$ and $8^{\text {th }}$ respectively. Respondents were most dissatisfied with location and access to social amenities. This is not surprising as the school is located off town, and social amenities such as market, and general commerce are not easily available on campus. It is also not surprising that respondents are not all that satisfied with the natural environment of the surrounding as there are only a few trees around the buildings that could provide shade and fresh natural air around the building. All the buildings are fixed with louvre blades which often have to be opened to admit fresh air. This makes it difficult to control the level of noise coming into the building from outside. This makes the ranking of this factor also low. The overall ranking of the buildings is

$$
A v \cdot R I I=\frac{0.72+0.73+0.78+0.52+0.83+0.41+0.86+0.51}{8}=0.67
$$

This means that the buildings assessed are slightly above satisfaction to the end users. 
Section $\mathrm{C}$ of the questionnaire required respondents to suggest measure that could be put in place to enhance users satisfaction. Key suggestions given by most of respondents include the following:

- Planting trees and flowers around the buildings to enhance fresh air around the buildings

- Changing the existing doors to glazed sliding doors and windows

- Putting air conditioners as a means of ventilation

- Making social amenities available and accessible on campus.

This study sought to:

i. Identify the factors that enhance end-users' satisfaction in these buildings.

ii. Identify factors within the building that cause end-users' dissatisfaction.

iii. Proffer remedial actions necessary to enhance end-users' satisfaction.

From the Literature Review, several factors were identified if well addressed would enhance end users satisfaction of buildings. These included indoor air quality, level lighting within the building, level of heat and ventilation, general appearance and greening environment around the building. The presence of social amenities was established from literature as a factor that enhances end-users satisfaction. This study confirms what was established from literature as users of the academic building facilities expressed their level of dissatisfaction or otherwise with these facilities.

As established from literature poor ventilation, lighting, air quality, natural environment, appearance of buildings and absence or inadequate social amenities are factors that cause end users dissatisfaction of buildings. In the current study, users expressed their dissatisfaction with some of these factors in the buildings that they use.

Consistent with the views expressed by respondents in answering the questionnaire, respondents proffered some suggestions that could enhance their level of satisfaction in using the buildings. They suggested amongst others that there should be trees and green plants planted around the buildings to provide natural fresh air into the building that could enhance ventilation. They also suggested that social amenities should be provided within the premises of the building that could enhance their satisfaction. It was suggested in addition that if the kind of windows and doors in use now are changed to glazed sliding doors and air conditioners used, ventilation, indoor air quality and noise level could be improved and hence users satisfaction.

\section{Conclusions}

From the analysis and discussion of the results as well as the review of the research objectives, it is apparent that the satisfaction of both students and employees regarding the use of building facility is slightly above average with RII value of 0.67 . It can be concluded from this study that all building facilities within the institution do not meet the desired level of satisfaction that students and employees desire. To a large extend, this conclusion hold good for buildings in other sister institutions within the Upper West Region and indeed the entire northern belt since the climatic conditions, level of economic development and architecture of buildings are virtually the same. It is imperative to indicate here however that this would be the case if the building design and orientation and wind direction are the same across different locations.

\section{Recommendations}

From the discussion so far it is hereby recommended that:

Conscious efforts should be made to plant trees and other green plants around buildings particularly in educational institutions to improve upon end-users satisfaction.

As part of long term development, institutions located off main commercial centers in town should be provided basic social amenities within their reach on campus to enhance user's satisfaction. To this end, local entrepreneurs need to be encouraged to explore this opportunity.

Indoor ventilation of building needs to be given a second look. Providing air conditioners and the use glazed sliding doors are highly recommended.

\section{Contributions to knowledge}

Post occupancy evaluation of buildings is an area that has not receive the much needed research attention particularly in Ghana. Thus this study is a modest contribution to scanty body of knowledge in the subject area.

\section{Area for further research}

Extant literatures suggest that end users satisfaction as a great impact of productivity. Thus it will be appropriate by way of further study, to do an assessment of impact of end users satisfaction on productivity.

\section{References}

Abbaszadeh, S., Zagreus, L., Lehrer, D., \& Huizenga, C. (2006). "Occupant satisfaction with indoor environmental quality in green buildings". Proceedings of Healthy Buildings. Lisbon , 3, 365-370.

Al-Ashwal, N. T., \& Hassan, A. S. (2018). “The Impact of Daylighting-Artificiel Lighting Integration on Building 
Occupant's Health and Performance”. International Journal Transaction Journal of Engineering Management \& Applied Sciences \& Technologies, 9, 97-105.

Altan, H., \& Zhang, Y. (2018). "Lighting Design in Workplace: A Case Study of a Modern Library Building in Sheffield", UK. Diunduh dari www. irbnet. de/daten/iconda/CIB17339. pdf, 27, 12.

ASHRAE Standard 55.(2013). Standard 55-2004-Thermal Environmental Conditions for Human Occupancy ASHRAE Inc., Atlanta, GA.

Ashrae, A., \& Standard, A. (2007). 62.1. 2007, "Ventilation for Acceptable Indoor Air Quality". American Society of Heating, Refrigerating and Air-Conditioning Engineers, Inc., Atlanta, GA.

ASHRAE. (2013). Handbook Fundamentals. Inc.: Atlanta, GA, USA: American society of heating, refrigerating and air-conditioning engineers.

ASHREA. (2010). Interactions Affecting the Achievement of Acceptable Indoor Environments.

Ayr, U., Cirillo, E., Fato, I. \& Martellotta, F. (2003). "A new approach to assessing the performance of noise indices in buildings". Applied Acoustics, 64, 129-145.

Balazova, I., Clausen, G., Rindel, J. H., Poulsen, T. \& Wyon, D. P. (2008). “Open-plan office environments: a laboratory experiment to examine the effect of office noise and temperature on human perception, comfort and office work performance". Proceedings of indoor air, 2008

Brace, I. (2004). "Questionnaire Design". (D. B. Birn, Ed.) London: Kogan Page Ltd.

Bryman, A. (2004). "Social Research Methods" (2nd Edition). Oxford: Oxford University Press.

Costanza, R., Fisher, B., Ali, S., Beer, C., Bond, L., Boumans, R., Snapp, R. (2007). "Quality of life: An approach integrating opportunities, human needs, and subjective well-being”. Ecological Economics, 61(2-3), 267-276. doi:http://dx.doi.org/10.1016/j.ecolecon.2006.02.023.

Danielsson, C. B. \& Bodin, L. (2009). "Difference in satisfaction with office environment among employees in different office types". Journal of Architectural and Planning Research, 241-257.

Dean, J. W., Ottensmeyer, E. \& Ramirez, R. (1997). “An aesthetic perspective on organizations”. Creating tomorrow's organizations: A handbook for future research in organizational behavior, 419-437

Dubois, M. C., Gentile, N., Bisegna, F., Knoop, M., Matusiak, B., Osterhaus, W., \& Tetri, E. (2016). T50 D. 2 Daylighting and lighting retrofit to reduce energy use in non-residential buildings: A literature review. A Technical Report from IEA SHC Task 50-Advanced Lighting Solution for Retrofitting Buildings.

Duffy, F., Laing, A. \& Crisp, V. (1992). “The responsible workplace”. Facilities, 10, 9-15

Enescu, D. (2017). "A review of thermal comfort models and indicators for indoor environments". Renewable and Sustainable Energy Reviews, 79, 1353-1379.

Evans, G.W., Bullinger, M., Hygge, S. (1998). "Chronic noise exposure and physiological response: a prospective study of children living under environmental stress". Psychological Science 9(1).

Frontczak, M., Schiavon, S., Goins, J., Arens, E. A., Zhang, H. P. D. \&Wargocki, P (2012). "Quantitative relationships between occupant satisfaction and satisfaction aspects of indoor environmental quality and building design". International journal of Indoor Environment and Health.

Gray, T. \& Birrell, C. (2014). "Are biophilic-designed site office buildings linked to health benefits and high performing occupants?" International journal of environmental research and public health, 11, 12204-12222.

Grinde, B. \& Patil, G. G. (2009). "Biophilia: does visual contact with nature impact on health and wellbeing?" International Journal of Environmental Research and Public Health, 6, 2332-2343

Guyot, G., Sherman, M. H., \& Walker, I. S. (2018). "Smart ventilation energy and indoor air quality performance in residential buildings": A review. Energy and Buildings, 165, 416-430.

Haider, M., Kerr, K. \& Badami, M. (2013). "Does Commuting Cause Stress? The Public Health Implications of Traffic Congestion". The Public Health Implications of Traffic Congestion (August 2, 2013).

Haynes, B. P. (2008a). "An evaluation of the impact of the office environment on productivity". Facilities, 26, $178-195$

Haynes, B. P. (2008b). "The impact of office layout on productivity". Journal of Facilities Management, 6, 189201.

Jahncke, H. \& Halin, N. (2012). "Performance, fatigue and stress in open-plan offices: The effects of noise and restoration on hearing impaired and normal hearing individuals". Noise and Health, 14, 260.

Kellert, S. R., Heerwagen, J. \& Mador, M. (2011). "Biophilic design: the theory, science and practice of bringing buildings to life", John Wiley \& Sons.

Kwallek, N., Lewis, C. M., \& Robbins, A. S. (1988). "Effects of Office Interior Color on Workers' Mood and Productivity". Perceptual and Motor Skills, 66, 123-128.

Langer, S. \& Bekö, G. (2013). "Indoor air quality in the Swedish housing stock and its dependence on building characteristics". Building and Environment, 69, 44-54.

Leaman, A. (1995). "Dissatisfaction and office productivity". Facilities, 13, 13-19

Leaman, A., \& Bordass, B. (2007). “Are users more tolerant of 'green' buildings?" Building Research \& Information, 35(6), 662-673.doi:10.1080/09613210701529518 
Lee, Y. S. (2010). "Office layout affecting privacy, interaction, and acoustic quality in LEED-certified buildings". Building and Environment, 45, 1594-1600.

Li, D. H. (2010). “A review of daylight illuminance determinations and energy implications”. Applied Energy, 87, 2109-2118.

Lohr, V. I., Pearson-Mims, C. H. \& Goodwin, G. K. (1996). "Interior plants may improve worker productivity and reduce stress in a windowless environment". Journal of Environmental Horticulture, 14, 97-100.

Mackerron, G. \& Mourato, S. (2013). "Happiness is greater in natural environments". Global Environmental Change, 23, 992-1000.

Mahnke, F. H. (1996). "Color, environment, and human response: an interdisciplinary understanding of color and its use as a beneficial element in the design of the architectural environment", John Wiley \& Sons.

Munsami, K., Prasad, D., \& Ding, L. (2017). "The role of post occupation evaluation in achieving high performance buildings through diagnostics". Procedia Engineering, 180, 356-364.

Mui, K. W., Wong, L.T.,(2006). "A method of assessing the acceptability of noise levels in air conditioned offices". Building Services Engineering Research and Technology; 27(3):249-254.

Nabhan, G. P., St Antoine, S., Kellert, S. \& Wilson, E. (1993). "The loss of floral and faunal story: The extinction of experience". The biophilia hypothesis, 229-250.

Narangerel, A., Lee, J. H., \& Stouffs, R. (2016). "Daylighting Based Parametric Design Exploration of 3D Facade Patterns".

Ng, L. C., Musser, A., Persily, A. K. \&Emmerich, S. J. (2012). "Indoor air quality analyses of commercial reference buildings". Building and Environment, 58, 179-187.

Omer, A. M. (2008). "Energy, environment and sustainable development". Renewable and sustainable energy reviews, 12, 2265-2300.

Ou, L. C., Luo, M. R., Woodcock, A. \& Wright, A. (2004). “A study of colour emotion and colour preference. part II: colour emotions for two-colour combinations. Color Research \& Application, 29, 292-298.

Öztürk, E., Yilmazer, S. \& Ural, S. E. (2012). "The effects of achromatic and chromatic color schemes on participants' task performance in and appraisals of an office environment". Color Research \& Application, 37, 359-366.

Parajuli, I., Lee, H., \& Shrestha, K. R. (2016). "Indoor Air Quality and ventilation assessment of rural mountainous households of Nepal". International journal of sustainable built environment, 5(2), 301-311.

Quang, T. N., He, C., Knibbs, L. D., De Dear, R. \&Morawska, L. (2014). "Co-optimisation of indoor environmental quality and energy consumption within urban office buildings". Energy and Buildings, 85, 225-234.

Rattananavathong, P., Jones, P. J., \& Lannon, S. (2017). "Dynamic lighting and cooling demand simulation in an urban context”.

Saunders, M., Lewis, P., \& Thornhill, A. (2009). "Research methods for business students", (5th ed.). Edinburgh Gate: Pearson Education Limited

Toftum, J., Lund, S., Kristiansen, J. \& Clausen, G. (2012). "Effect of open-plan office noise on occupant comfort and performance". 10th International Conference on Healthy Buildings.

Van Der Voordt, T. J. (2004). "Productivity and employee satisfaction in flexible workplaces". Journal of Corporate Real Estate, 6, 133-148.

Van Duijnhoven, J., Aries, M. B. C., Rosemann, A., \& Kort, H. S. M. (2016). "Light ratios, satisfaction, user perception, and general health in (day) lit office landscapes". 22. Internationale Tagung Licht, 25-29.

Veitch, J. A., Farley, K. M. \& Newsham, G. R. (2002). "Environmental satisfaction in open-plan environments": 1. Scale validation and methods.

Vischer, J. (2008). "Towards an Environmental Psychology of Workspace: How People are Affected by Environments for Work". Architectural Science Review, 51(2), 97-108. doi:10.3763/asre.2008.5114

Wang, Z., de Dear, R., Luo, M., Lin, B., He, Y., Ghahramani, A., \& Zhu, Y. (2018). "Individual difference in thermal comfort: A literature review". Building and Environment, 138, 181-193.

World Green Building Council (2014). "Health, Wellbeing \& Productivity in Offices". World Green Building Council.

Yi, J. I. N., Wang, F., Carpenter, M., Weller, R., Tabor, D., \& Payne, S. (2020). "The effect of indoor thermal and humidity condition on the oldest-old people's comfort and skin condition in winter". Building and Environment, 106790.

Yildirim, K., Akalin-Baskaya, A. \& Celebi, M. (2007). "The effects of window proximity, partition height, and gender on perceptions of open-plan offices". Journal of Environmental Psychology, 27, 154-165. Z

Yin, R. K. (2003). "Case Study Research: Design and methods”, (3rd ed.). Thousand Oaks, CA: Sage. 